\title{
Exploring the Rationale of Performance Based Funding for Malaysian Public Universities
}

\author{
Abd Rahman Ahmad
Kek Siok Yee
(D) \\ Abd Rahman Ahm
Kek Siok Yee ${ }^{2}$ iD \\ Alan Farley ${ }^{3}$
}

${ }^{2}$ Faculty of Technology Management and Business, Universiti Tun Hussein Onn Malaysia, Johor, Malaysia Email:arahman@uthm.edu.my.Tel.+60745s9989

Email. keksiokyee@gmail.com

${ }^{3}$ School of Accounting and Finance, Faculty of Business and Law, Victoria University of Melbourne, Australia

'Email:Alan.Farley@vu.edu.au

\section{Abstract}

The intention of this paper is to discuss the rationale for Malaysian public universities to implement Performance Based Funding (PBF) mechanism. Here, the funding mechanisms are systems based on allocating a proportion of education budgets relative to specific performance measures such as course completion, credit attainment, and degree completion, instead of allocating funding entirely based on enrolment alone. The implementation of PBF mechanisms has recently become a topic of heated debate in the education sector worldwide which has also increased the interest of researchers and policymakers to work on it. Since almost no study has looked into the applicability of PBF in Malaysia with the aims to contribute knowledge and fill the gap in the current research. Semi-structured interviews were conducted to answer the objective of this study. The positive functions of qualitative research methodology are to show that it can assist the researcher in obtaining in-depth information and to understand the subjective experience of the respondents. Thus, in this procedure, semi-structured interviews were adopted and targeted to obtain information regarding the applicability of the PBF mechanism from the budgeting and financial aspects. Participants who encompassed in semi-structured interviews were the senior officer from the Bursar Office of selected universities. The findings from the qualitative data showed that PBF mechanism is suitable to be implemented at Malaysian public universities. However, there were several issues that the government needs to be addressed before the PBF mechanism can be successfully implemented.

Keywords: Performance based funding, Funding, Higher education, Public University, Performance indicator, Strategic plan.

Citation | Abd Rahman Ahmad; Kek Siok Yee; Alan Farley (2020) Exploring the Rationale of Performance Based Funding for Malaysian Public Universities. Journal of Education and e-Learning Research, 7(1): 15-21.

History:

Received: 8 October 2019

Revised: 12 November 2019

Accepted: 16 December 2019

Published: 10 February 2020

Licensed: This work is licensed under a Creative Commons

Attribution 3.0 License (c)

Publisher: Asian Online Journal Publishing Group
Acknowledgement: All authors contributed to the conception and design of the study.

Funding: The authors would like to thank you to Research Management Office (RMC), Universiti Tun Hussein Onn Malaysia for allowed this paper to be presented by covering fees by using research fund (E15501) UTHM. Competing Interests: The authors declare that they have no conflict of interests.

Transparency: The authors confirm that the manuscript is an honest, accurate, and transparent account of the study was reported; that no vital features of the study have been omitted; and that any discrepancies from the study as planned have been explained.

Ethical: This study follows all ethical practices during writing.

\section{Contents}

1. Introduction

3. Research Methodology 


\section{Contribution of this paper to the literature}

This study contributes to existing literature by discussing the rationale for Malaysian public universities to implement Performance Based Funding (PBF) mechanism.

\section{Introduction}

The implementation of PBF mechanisms is prevalent in developed or developing countries today. Malaysian government currently takes the initiative to implement PBF mechanisms as highlighted in the National Higher Education Action Plan 2007-2010, Tenth Malaysian Plan 2011-2015, Eleventh Malaysian Plan 2016-2020 and Malaysian Education Blueprint 2015-2025 (Higher Education) (MoHE, 2007a; EPU, 2010; EPU, 2015; MoHE, 2015). The implementation of PBF in higher education is justified with the concept that public funds should be used efficiently and effectively (Teixeira et al., 2014). In terms of efficiently, the universities are envisaged to maximise their output and performance, such as research output, institution rankings, and employability using the money allocated to them. In terms of effectiveness, the universities are envisaged to be responsible to their universities objective and their role to the nation such as to grant quality degrees and to perform basic and applied research. PBF was recommended in order to reduce the dependency of Malaysian public universities on funding committed by the government, which about 75 to 90 per cent (Berita, 2015). The implementation of PBF is also designed to stimulate competition between universities and at the same time increase autonomy, as highlighted in the government policy, accountability and the transparency required in spending public funds (MoHE, 2007a; EPU, 2010; 2015; MoE, 2015). Here, PBF is expected to alter the behaviour of the universities (Miller and Morphew, 2017). According to Kivistö (2005) the implementation of PBF aims to align the interests and goals of the universities with the government's intended outcomes. Moreover, it forms a closer relationship between the government and universities. Hence, agency theory can be used to study the relationships between government and universities. There are two vital components that have been identified as contributing to the applicability of a PBF mechanism in a country, which is alignment to the government's objectives and the level of understanding of PBF (Kaullychurn, 2009). Ahmad and Farley (2013b) pointed out that adequate autonomy and financial freedom should be given to universities before the implementation of PBF mechanism. Critical elements such as purpose, performance indicators, success criteria, indicator weights, allocation methods, and funding levels are also important to the establishment of PBF (Serban, 2000; Dougherty, 2018).

\section{Performance Based Funding}

$\mathrm{PBF}$ is recognised as a transformation approach from traditional funding. It is increasingly popular in higher education worldwide. It is a mechanism which emphasises on quality rather than quantity (Marks and Caruthers, 1999; Ahmad, 2013). With PBF, universities are funded based on their actual performance such as the funding allocation is determined through the degree completion of students instead of the enrolment of students (Salmi and Hauptman, 2006; Hillman et al., 2013). As PBF ensures the funds are directly allocated to those universities with outstanding achievement, it can maximise the return on funding and taxpayer money (Klein, 2015). PBF can also create a competitive environment in academia as a result of universities compete for their performances for funding allocation, which therefore can stimulate academics to exert more efficiently (Taylor and Taylor, 2003; Umbricht et al., 2017).

The implementation of PBF mechanisms is identified as the most frequently and probably effective method that can drive universities to behave following government's desired objectives and outcome (Zusman, 2005; Schiller and Liefner, 2007). Besides, it shows the ability to improve the efficiency, accountability and quality of higher education institutions (Frølich, 2008). The implementation of PBF mechanisms is identified as the most frequent and effective method that can drive universities to follow and meet the government's objectives and outcomes (Zusman, 2005; Schiller and Liefner, 2007). Additionally, it also shows the ability to improve the efficiency, accountability, and quality of HEIs (Frølich, 2008). In practice, there are four types of PBF mechanisms which are discussed below:

\section{1) Performance contracts}

Performance contracts are agreements between the government and the respective university after the level of funding and objectives have been determined and agreed (Strehl et al., 2007a). Salmi and Hauptman (2006) stated that even though this type of funding method is typically viewed as an incentive, it may also act as a punitive action if the university is unable to meet the agreed goals. Consequently, performance contracts may look like a good deal where the government is 'buying' a particular kind of performance from the university (Jongbloed, 2010; Ziskin et al., 2018).

2) Performance set-asides

Performance set-asides refer to the portion of a budget reserved for particular universities whose performance is being measured. This funding may be extracted from either the base funding or from an additional source (Miao, 2012) and has been used by South Africa and the United States (Salmi and Hauptman, 2006).

\section{3) Competitive funding}

Competitive funding is a subset of PBF mechanisms. Funding will be given to those selected candidates with a successful proposal after being subject to a peer review (Ahmad, 2013). This funding method aims to improve the quality of academia and at the same time promote transparency and accountability in managing public funds (Salmi and Hauptman, 2006; Ziskin et al., 2018).

4) Payment for results

Payment for results is also an approach of PBF mechanisms where the amount of the funding is distributed based on the output or the output measured either through a formula or as a separate set of payments (Salmi and 
Hauptman, 2006; Dougherty, 2018). This type of funding method has been implemented in Denmark, Norway, England, and the Netherlands (Salmi and Hauptman, 2006).

\subsection{Performance-based funding indicators}

$\mathrm{PBF}$ is a mechanism that involves specified performance indicators directly connected to the institution funding which reflects the public objectives rather than the HEIs need (Salmi and Hauptman, 2006). PBF aims to strengthen the initiatives that promote excellence in research as well as teaching and learning (T\&L). Most of the HEIs across the globe have adopted PBF mechanisms that rely on performance indicators (Jongbloed and Vossensteyn, 2001; Dougherty, 2018). Performance indicators in the PBF mechanism are varied according to the appropriateness of the country's higher education system. Furthermore, Layzell (1998) stated that there are five primary uses for performance indicators which consist of monitoring, evaluation, dialogue, rationalisation, and resources allocation. Qualitative and quantitative performance indicators under the PBF mechanism are usually used to measure the quality of the research or teaching at the institution (Kaullychurn, 2009). Kivistö (2005) also stated several outcome indicators measure teaching activities such as the number of master's degrees granted, number of study credits collected, number of exams passed or the number of graduates working in jobs related to their study field. Whilst the outcome indicators normally measure research activities such as the number of research publications, the number of doctoral degrees granted, or the number of patents received. In the following section, a summary of performance indicators used in higher education has been outlined in Table 1 .

Table-1. Summary of performance indicators.

\begin{tabular}{|c|c|c|c|}
\hline No & Source & Teaching & Research \\
\hline 1 & $\begin{array}{l}\text { Selected performance indicators in } \\
\text { higher education } \\
\text { Cave } \text { et al. (1989) }\end{array}$ & $\begin{array}{l}\text { - } \quad \text { Cost per student or ratio } \\
\text { - Value-added } \\
\text { - } \quad \text { Rate of return } \\
\text { - Wastage and non-completion rates } \\
\text { - } \quad \text { Employment on graduating or } \\
\text { - } \quad \text { after five years } \\
\end{array}$ & $\begin{array}{ll}\text { - } & \text { Number of research } \\
\text { - } & \text { students } \\
\text { - } & \text { Researcations patents } \\
\text { - } & \text { Research income } \\
\text { - } & \text { Peer review } \\
\text { - } & \text { Reputational ranking } \\
\end{array}$ \\
\hline 2 & $\begin{array}{l}\text { Variables for analysing HEIs in } \\
\text { Europe } \\
\text { Bonaccorsi and Daraio (2007) }\end{array}$ & $\begin{array}{ll}\text { - } & \text { Number of undergraduate students } \\
\text { - } & \text { Number of undergraduate degrees } \\
\text { - } & \text { Number of PhD students } \\
\text { - } & \text { Number of PhD degrees }\end{array}$ & $\begin{array}{ll}\text { - } & \text { ISI publications } \\
\text { - } & \text { Other publications } \\
\text { - } & \text { Licensing revenues } \\
\text { - } & \text { Patents held } \\
\text { - } & \text { Spin-off companies formed } \\
\end{array}$ \\
\hline 3 & $\begin{array}{l}\text { Teaching and research indicators in } \\
\text { Australia } \\
\text { Guthrie and Neumann (2007) }\end{array}$ & $\begin{array}{ll}\text { - } & \text { Student load by category } \\
\text { - } & \text { Student load \% of the sector } \\
\text { - } & \text { International student as \% of the } \\
\text { institution's load } \\
\text { - } & \text { EFTSU (equivalent full-time } \\
\text { - } & \text { Equity } \\
\text { - } & \text { Indigenous }\end{array}$ & 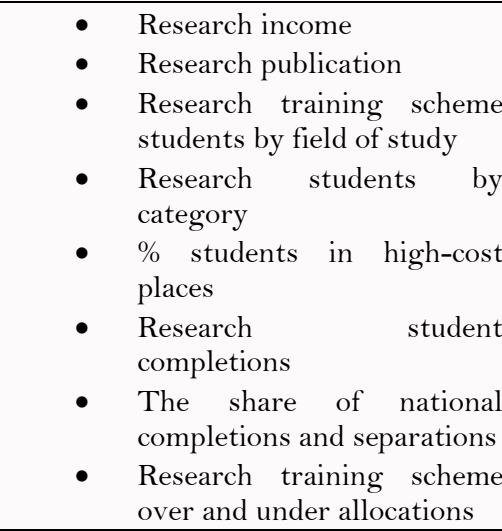 \\
\hline
\end{tabular}

\subsection{Public University in Malaysia}

Malaysian public universities are country's institutions or agents for societal development and human capital formation (Sirat and Kaur, 2010). By referring to the National Higher Education Strategic Plan beyond 2020, Malaysian public universities are divided into three categories, which are Research/Apex Universities (RAUs), Comprehensive Universities (CUs), and Focused Universities (FUs) where each category has its own characteristics and responsibilities (MoHE, 2007b). Up to date, out of a total of 20 public universities in Malaysia, there are five RAUs, four CUs, and 11 FUs.

The main concerns around implementing a PBF mechanism are definitely the appropriate designs which involve the selection of the right indicators and measures to evaluate institutions and with the development of appropriate rewards programs (Salmi and Hauptman, 2006). Generally, PBF is introduced to control the institutions focus on particular outcomes and those institutions that are compliant with the government priorities are financially rewarded (De Boer et al., 2015). However, the choice of performance indicators appears to always emerge as the main controversial issue when implementing the PBF mechanisms (Jongbloed and Vossensteyn, 2001; Dougherty, 2018). Furthermore, Ahmad et al. (2013a) pointed out that it is difficult to justify the criteria of priorities in determining the funding weights for each of the indicators.

Therefore, in order to ensure the success and the effectiveness of implementing PBF mechanisms, Layzell (1998) summarised the factors required including (1) the number of performance indicators selected should be kept to a minimum as below 20; (2) the performance indicators should not be implemented in a top-down manner; (3) the development of the indicators should involve the faculty and the state legislature for long-term success; (4) one type of indicator model cannot be applied to all types of institutions; (5) qualitative measurement is preferable to be used rather than the quantitative measurement by the policymakers; (6) appropriate financial incentives should be allocated to every indicator and given to the qualified institutions; and (7) the results of the performance should be reported to the policymakers and the general public in a timely and understandable fashion. Furthermore, Kivistö (2005) stated that the indicators chosen by the government not only have to be relevant for measuring performance but also have to be liable to a broader social and economic environment. 
Following this, the implementation of PBF mechanisms has shown a high potential in improving performance in higher education (Layzell, 1998). It has been highlighted that the implementation of PBF could improve efficiency and value for money, promote quality, and enhance the accountability of HEIs (Kaullychurn, 2009). Furthermore, the competitiveness of PBF could also act as a marketing tool which enables universities to compete against each other in order to obtain higher levels of funding and encourage the universities to offer a higherquality of teaching and research, as well as to foster educational and organisational innovation (Liefner, 2003). In order to enhance the universities' performance, the funding relationship between the government and funded universities had been redefined by using PBF. Previous research has shown that one of the main factors which attribute to the reformation of government funding is the implementation of PBF (Schiller and Liefner, 2007; Ahmad and Farley, 2013b). Nevertheless, Schiller and Liefner (2007) stated that changing to a new funding mechanism is expected to alter the behaviour of the universities. The rising concern of using taxpayers' money has resulted in the government urging the universities to be more economically astute whilst fulfilling the goals outlined in the government's strategic plan (Lane and Kivisto, 2008). Therefore, funding can be used as a strategic plan to align the universities' behaviour with the government objectives (Frølich et al., 2010). In addition, Ahmad et al. (2013a) have proposed three control methods that are applicable for the government to control the agents by creating efficient monitoring systems, instituting bonds and promissory arrangements, and lastly to establish effective financial incentives that link the rewards with the agents' performances.

\subsection{The Rationale of $P B F$}

In practice, Malaysian public universities heavily rely on government funding for their operational and development expenditure. The funding is given to the universities on the basis of negotiation with the government (World Bank/EPU, 2007). A total of 90 per cent of the funding is contributed by the government for Malaysian public universities (Lee, 2000; MoHE, 2007b; Ahmad and Farley, 2013b). With reference to the Malaysian Education Blueprint 2015-2025 (Higher Education), Malaysia government was found to be the highest among other countries which funded about 7.7 per cent of its annual budget for the higher education sector (MoE, 2015). However, in reality, the increasing demand for efficiency and innovativeness in spending public fund has caused the use of the traditional method of funding to become inadequate (World Bank/EPU, 2007). Moreover, the traditional method of funding has resulted in an array of issues, including the level of funding does not in relation to performances of universities (World Bank/EPU, 2007) funding did not use efficiently and too much dependence on funding committed by the government (Berita, 2015). Indeed, governance and financing have been pointed out is a central issue to address while ensuring the development of Malaysian universities (World Bank/EPU, 2007). PBF was found to be the most relevant method that can assist the Malaysian government in saving up to 10 to 30 per cent of the operational funds for public universities (World Bank/EPU, 2007). The connection between funding and performance is targeted to improve efficiency by encouraging institutions to reduce costs and eliminate low priority expenditures (Orr, 2005; Kaullychurn, 2009). Additionally, a recent study by Ahmad (2013) stated that PBF can aid the Malaysian government to reduce the goal conflict and information asymmetry with public universities. The results indicate that the universities' objective is parallel with the government's desired outcomes through the implementation of PBF mechanism. Besides, autonomy needs to be granted to universities as it plays an important role in the implementation of PBF (Kivistö, 2005; 2008; Ahmad, 2013). Autonomy is required for the universities to manage the funding which respect to their daily financial operation (Sirat, 2010).

\section{Research Methodology}

In this study, semi-structured interviews were conducted to obtain information from the potential respondents. The population of this study included all Malaysian public universities. Furthermore, the samples used for the semi-structured interview were senior officer from the Bursar Office of selected universities. However, due to the ethical consideration and to enclose the identity of the selected universities, the results from the selected universities were coded as University A, B, C and D. In this study, participants who encompassed in semistructured interviews were the senior officer from the Bursar Office of selected universities. Senior officers from the Bursar Office are the most suitable resources used in this study as they possess the experience and knowledge in managing and preparing the budget of their university. Therefore, they were selected as participants in this research interviews to share their views or perspectives. The job scope for the Bursar Senior Officer is summarised in Table 2 .

Table-2. Job descriptions

\begin{tabular}{l|l}
\hline Position & General Job Descriptions \\
\hline Bursar Senior Officer & - Be responsible for managing the university's budget. \\
& - Preparing operating budget. \\
& - Preparing distribution for management and development. \\
& - Adjustment and transfer if government agencies. \\
& - Responsibility for preparing the university's budget report. \\
\hline
\end{tabular}

Source: Ahmad et al. (2013a).

Four semi-structured interviews were conducted in four Malaysian public universities according to the university category, with one from RAUs, one from CUs, and two from FUs. The interview questions were validated by the supervisor. Interview sessions with the participant from each of the universities were conducted by using the face to face method and based on the participant's availability. The interview sessions were carried out inappropriate languages and were recorded with the permission of the participants. The interview guidelines were sent to each of the participants via email before the interview session in order to give them an opportunity to prepare. All interview sessions lasted approximately one hour. 


\subsection{Data Analysis}

Interview sessions with the respondents from each category of Malaysian public universities were conducted based on the respondents' availability. An Interactive Model which was proposed by Miles and Huberman (1994) is shown in Figure 1 was used for data analysis when all the data is completely collected.

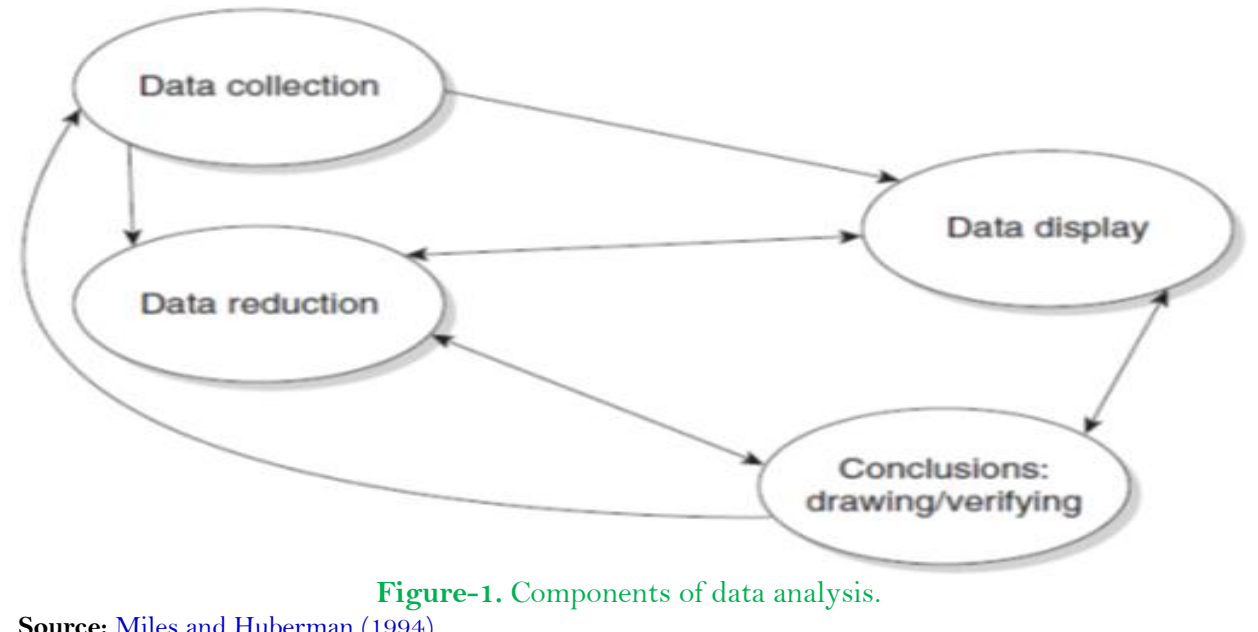

The Interactive Model consists of three stages including data reduction, data display, and conclusion. Data reduction is the first stage of data analysis. In this stage, the data collected underwent the process of selecting, focusing, simplifying, extracting, and transforming (Miles and Huberman, 1994). Furthermore, only the data which is related to this study were taken into account and coded according to the themes that were drawn from the research questions. The second stage of the data analysis is the data display. In this stage, the data was displayed in the relevant form and arranged by using a matrix method. The data displayed in the data display matrices guided the researcher to draw the conclusions of the study relatively easily. Lastly, the data which is used for the conclusion was generated at the last stage of the data analysis and based on the research questions. In order to ensure the reliability of the conclusion, a cross-checking data process is carried out to verify the conclusion of the study.

Findings from the semi-structured interviews are used to develop the items in the survey questionnaire form. The interviews were conducted at four participating public universities. One RAU, one CU, and two FUs were selected from each category of Malaysian public universities. In order to protect the identity of the universities, the name of the universities will not be revealed and they were labelled as University A, B, C, and D. In this chapter, the results of research question one, followed by a summary of the qualitative findings are presented.

\section{Discussion}

Government objectives were identified by participants as one of the major drivers that contributed to the implementation of a PBF mechanism. In the current study, government objectives comprise of monitoring the universities performances, reporting information on achievement, motivating the universities, reducing goal conflict and/or information asymmetry, and accountability and the transparency needed in managing public funds.

The participants in the semi-structured interviews pointed out that the implementation of a PBF mechanism may see an increase in the level of monitoring activities by the government. The government can use all information obtained from the KPIs, monitoring and control mechanisms for monitoring the universities' performances and for the purpose of the allocation of funds. To ensure the effectiveness of monitoring activities, the government is advised to provide clear guidelines before implementing a PBF mechanism.

In addition, the results of this study indicated that the implementation of a PBF mechanism will increase the universities level of accountability and transparency in managing public funds. In addition, it will also improve the accuracy of the information provided by them with the adoption of KPIs, monitoring and control mechanisms. Results from the qualitative interviews found that the participants agreed that the implementation of PBF mechanism will motivate the universities to achieve their targeted KPIs. In contrast, the government needs to set the KPIs based on the circumstances of each university to avoid demotivating. Moreover, the implementation of a PBF mechanism needs to be driven by incentives. In addition, it is found that the universities will work more effectively in line with government objectives and will ultimately reduce information asymmetry and/or goal conflict because of the incentives provided.

From the participant's perspective, the level of understanding is regarded as the main variable in implementing a PBF mechanism. In this study, the level of understanding included an understanding of the PBF mechanism, the appropriateness of the PBF mechanism implementation, the platform to implementing the PBF mechanism, area focus on the implementation of PBF mechanism, and critical success factors for a PBF mechanism implementation. Here, a higher level of PBF understanding indicates a higher success rate of a PBF mechanism implementation.

The results of this study indicated that the participants were aware of this PBF mechanism, and always align themselves with the government's policy. The government goals to implement the PBF mechanism are clearly highlighted in the National Higher Education Action Plan 2007-2010, Tenth Malaysian Plan 2011-2015, Eleventh Malaysian Plan 2016-2020, and Malaysian Education Blueprint 2015-2025 (Higher Education). Results from the qualitative data show that there is a mixed perception of the appropriateness of a PBF mechanism implementation in Malaysian public universities. In contrast, it is found that the majority of the participants' universities in the interviews agreed that a PBF mechanism is the appropriate tool to be implemented in Malaysian public universities.

The study has found that the categorisation of Malaysian public universities can be used by the government as a platform to implement a PBF mechanism. This argument is based on results obtained from the semi-structured 
interviews with the participants. However, the same targets should not be set for different university category when implementing this PBF mechanism. This is due to each university category has its own nature and specialisation. Moreover, the results from this study demonstrated that the participants have different viewpoints on the area that should be focused on the implementation of PBF mechanism. This is due to the fact that the government currently implemented categorisation to Malaysian public universities. Furthermore, the qualitative data further explored the critical success factors for the PBF mechanism implementation. The participants from the universities identified that readiness, autonomy, management, incentives, and comprehensive framework and foundation are the factors that contributed to the success of PBF mechanism implementation in Malaysian public universities.

In relation to the government initiative to implement PBF mechanism in Malaysian public universities, participants agreed that PBF mechanism could improve the accuracy of the information from public universities to the government even more. This was then further supported by a participant from University $\mathrm{C}$ but noted that the measurement mechanism should be carefully selected. For example, the information should not extract from the questionnaire. This is due to every respondent has their own interpretation towards the questionnaire received which may cause the information collected to become inaccurate.

Next, findings collected from the semi-structured interviews showed that participants have similar perception and agreed that PBF mechanism will lead to increase in monitoring activities by the Malaysian Federal Government or Ministry of Higher Education (MoHE) as a principal. However, participants from University A and $\mathrm{B}$ further pointed out that the government needed to have an early preparation before they can monitor the universities.

Additionally, findings from the participants indicated that the PBF mechanism could increase the level of accountability and transparency of public universities in managing public funds. Furthermore, as universities are funded by the public, a participant from University D further reported that public universities must have the responsibility to be transparent and accountable. They cannot compromise on this matter. They are requested to ensure that the funding is able to contribute to better performance.

Meanwhile, findings collected from the semi-structured interviews also indicated that PBF mechanism could increase the motivation of the public universities. The university will try to achieve the KPI and at the same time provide the training to the staff as stated by participant from University D. However, participants from University $\mathrm{B}$ and $\mathrm{C}$ also noted that PBF mechanism may bring negative effect to the universities if the government do not set the KPIs according to the conditions of each university. However, participants in this study stated that autonomy should be followed with the implementation of PBF mechanism at Malaysian public universities. They are critically desired to be given autonomy by the government. The autonomy given could allow them to manage their university funding with the KPIs set by the government.

This study produced results that confirmed the findings of a substantial amount of previous work that examined the significance of government objectives in enhancing the success of a PBF mechanism implementation. These findings are in agreement with numerous studies such as Ahmad et al. (2013a) and Kaullychurn (2009) which show a positive relationship between government objectives and PBF mechanism implementation. More importantly, this study supports the argument that the implementation of a PBF mechanism may show an increase in the monitoring activities by the government (Ahmad, 2013) an increase in the level of accountability and transparency by the universities in managing public funds (Kaullychurn, 2009; Friedel et al., 2013) improve the accuracy of the information provided by the universities (Ahmad, 2013) motivate the universities to achieve their KPIs (Dougherty and Reddy, 2011) as well as reducing information asymmetry and/or goal conflict (Verhoest, 2005; Ahmad, 2013). Additionally, the findings of this study also provided additional evidence that incentives should be provided along with the implementation of a PBF mechanism to make universities work more effectively in line with government objectives and ultimately reduce information asymmetry and/or goal conflict (Verhoest, 2005).

\section{Conclusion}

In conclusion, several advantages were identified could increase the rationale for Malaysian public universities to implement PBF mechanism. There are altogether four advantages, which are PBF mechanism could improve the information accuracy given by the public universities, increase in monitoring activities, increase the level of accountability and transparency of public universities in managing public funds and lastly increase the motivation of the public universities. However, the results also revealed that autonomy is found to be an important element that contributes to the successfulness of PBF mechanism implementation.

\section{References}

Ahmad, A.R., 2013. The impact of government funding reforms on the strategic planning of Malaysian public universities. Victoria University of Melbourne Australia: Ph.D. Thesis.

Ahmad, A.R. and A. Farley, 2013b. Federal government funding reforms: Issues and challenges facing Malaysian public universities. International Journal of Asian Social Science, 3(1): 282-298.

Ahmad, A.R., A. Farley and M. Naidoo, 2013a. Funding crisis in higher education institutions: Rationale for change. Asian Economic and Financial Review, 2(4): 562-576.

Berita, H., 2015. Five percent of public university funds are reserved 2016. Berita Harian, 25 November 2015.

Bonaccorsi, A. and C. Daraio, 2007. Universities and strategic knowledge creation: Speclialization and performance. Edward Elger Publishing Limited.

Cave, M., M. Kogan and S. Hanney, 1989. 'Performance measurement in higher education'. Public Money \& Management, 9(1): 11-16.

De Boer, H., B. Jongbloed, P. Benneworth, L. Cremonini, R. Kolster, A. Kottmann and H. Vossensteyn, 2015. Performance-based funding and performance agreements in fourteen higher education systems. Center for Higher Education Policy Studies.

Dougherty, K.J., 2018. Performance-based funding, higher education in the US: In encyclopedia of international higher education systems and institutions. Dordrecht: Springer. pp: 1-5.

Dougherty, K.J. and V. Reddy, 2011. The impacts of state performance funding systems on higher education institutions: Research literature review and policy recommendations. Teachers College, Columbia University: Community College Research Center.

EPU, 2010. Tenth Malaysia Plan 2011-2015. Putrajaya, Malaysia: Economic Planning Unit.

EPU, 2015. Tenth Malaysia Plan 2011-2015. Putrajaya, Malaysia: Economic Planning Unit. 
Friedel, J.N., Z.M. Thornton, M.M. D’Amico and S.G. Katsinas, 2013. Performance-based funding: The national landscape. U. o. AEP Center (Ed.): 20.

Frølich, N., 2008. The politics of steering by numbers: Debating performance-based funding in Europe. NIFU STEP.

Frølich, N., E.K. Schmidt and M.J. Rosa, 2010. Funding systems for higher education and their impacts on institutional strategies and academia. International Journal of Educational Management, 24(1): 7-21.Available at: https://doi.org/10.1108/09513541011013015.

Guthrie, J. and R. Neumann, 2007. Economic and non-financial performance indicators in universities: The establishment of a performancedriven system for Australian higher education. Public Management Review, 9(2): 231-252.Available at: https://doi.org/10.1080/14719030701340390.

Hillman, N., R. Kelchen and S. Goldrick-Rab, 2013. Recommendations for the effective and equitable implementation of performance-based funding for Wisconsin Higher Education. WISCAPE Policy Brief. Madison, WI: University of Wisconsin-Madison, Wisconsin Center for the Advancement of Postsecondary Education (WISCAPE).

Jongbloed, B., 2010. Funding higher education: A view across Europe. Bruxelles: European Centre for Strategic Management of Universities.

Jongbloed, B. and H. Vossensteyn, 2001. Keeping up performances: An international survey of performance-based funding in higher education. Journal of Higher Education Policy and Management, 23(2): 127-145.Available at: https://doi.org/10.1080/13600800120088625.

Kaullychurn, S., 2009. Applicability of performance-based funding models for tertiary education in SIDS - The case of mauritius. Victoria University of Wellington: Ph.D. Thesis.

Kivistö, J., 2005. The government-higher education institution relationship: Theoretical considerations from the perspective of agency theory. Tertiary Education \& Management, 11(1): 1-17.Available at: https://doi.org/10.1080/13583883.2005.9967136.

Kivistö, J., 2008. An assessment of agency theory as a framework for the government-university relationship. Journal of Higher Education Policy and Management, 30(4): 339-350.Available at: https://doi.org/10.1080/13600800802383018.

Klein, S.G., 2015. Using performance-based funding to incentivize change (RTI Press publication OP-0020-1501). Research Triangle Park, NC: RTI Press.

Lane, J. and J. Kivisto, 2008. Interests, information, and incentives in higher education: Principal-agent theory and its potential applications to the study of higher education governance. Higher Education, 23: 141-179.

Layzell, D.T., 1998. Linking performance to funding outcomes for public institutions of higher education: The US experience. European Journal of Education, 33(1): 103-111.

Lee, M.N.N., 2000. The impacts of globalization on education in Malaysia. In: Stromquist, N. P. \& Monkman, K. (Ed.), Globalization and Education: Integration and Contestation across Cultures. Lanham, MD: Rowman \& Littlefield.

Liefner, I., 2003. Funding, resource allocation, and performance in higher education systems. Higher Education, 46(4): 469-489.

Marks, J.L. and J.K. Caruthers, 1999. Funding public higher education in the 1990s: What happened and where are we going? , New York.

Miao, K., 2012. Performance-based funding of higher education: A detailed look at best practices in 6 states. Center for American Progress.

Miles, M.B. and A.M. Huberman, 1994. Qualitative data analysis: An expanded sourcebook. 2nd Edn., Thousand Oaks, California: SAGE Publications, Inc.

Miller, G.N. and C.C. Morphew, 2017. Merchants of optimism: Agenda-setting organizations and the framing of performance-based funding for higher education. The Journal of Higher Education, 88(5): 754-784.Available at: https://doi.org/10.1080/00221546.2017.1313084.

MoE, 2015. Malaysia education blueprint 2015 - 2025 (Higher Education). Putrajaya.

MoHE, 2007a. National higher education action plan 2007 - 2010. Putrajaya, Malaysia: Ministry of Higher Education.

MoHE, 2007b. National higher education strategic plan extends 2020. Putrajaya, Malaysia: Ministry of Higher Education.

MoHE, 2015. Malaysia education blueprint 2015 - 2025 (Higher Education). Putrajaya, Malaysia: Ministry of Higher Education.

Orr, D., 2005. Can performance-based funding and quality assurance solve the state vs market conundrum? Higher Education Policy, 18(1): 31-50.Available at: https://doi.org/10.1057/palgrave.hep.8300071.

Salmi, J. and A.M. Hauptman, 2006. Innovations in tertiary education financing: A comparative evaluation of allocation mechanisms. . World Bank Education Working Paper Series, No. 4.

Schiller, D. and I. Liefner, 2007. Higher education funding reform and university-industry links in developing countries: The case of Thailand. Higher Education, 54(4): 543-556.Available at: https://doi.org/10.1007/s 10734-006-901 1-y.

Serban, A.M., 2000. Newcomers to performance funding: A comparison of California's partnership for excellence to other performance funding programs. Paper Presented at the Annual Forum of the Association for Institutional Research, 21-24 May 2000, Cincinnati, Ohio.

Sirat, M. and S. Kaur, 2010. Changing state-university relations: The experiences of Japan and lessons for Malaysia. Comparative Education, 46(2): 189-205.Available at: https://doi.org/10.1080/03050061003775520.

Sirat, M.B., 2010. Strategic planning directions of Malaysia's higher education: University autonomy in the midst of political uncertainties. Higher Education, 59(4): 461-473.Available at: https://doi.org/10.1007/s 10734-009-9259-0.

Strehl, F., Reisinger and Kalatschan, 2007a. Funding systems and their effects on higher education system. OECD Education Working Papers.

Taylor, J. and R. Taylor, 2003. Performance Indicators in Academia: An X-Efficiency Approach? Australian Journal of Public Administration, 62(2): 71-82.Available at: https://doi.org/10.1111/1467-8497.00326.

Teixeira, P., R. Biscaia and V. Rocha, 2014. Competition and performance in European higher education: The role of funding instruments. Education Pages, 7(2): 61-80.

Umbricht, M.R., F. Fernandez and J.C. Ortagus, 2017. An examination of the (un) intended consequences of performance funding in higher education. Educational Policy, 31(5): 643-673.Available at: https://doi.org/10.1177/0895904815614398.

Verhoest, K., 2005. Effects of autonomy, performance contracting, and competition on the performance of a public agency: A case study. Policy Studies Journal, 33(2): 235-258.Available at: https://doi.org/10.1111/j.1541-0072.2005.00104.x.

World Bank/EPU, 2007. Malaysia and the hnowledge economy: Building a world-class higher education system. Human Development Sector Reports East Asia and the Pacific Region: The World Bank.

Ziskin, M.B., K.E. Rabourn and D. Hossler, 2018. Performance-based funding of higher education: Analyses of policy discourse across four case studies. Journal for Critical Education Policy Studies, 16(2): 164-210.

Zusman, A., 2005. Challenges facing higher education in the twenty-first century. American Higher Education in the Twenty-First Century: Social, Political, and Economic Challenges, 2: 115-160. 